\title{
Proposta para a estimação da corrupção regional no Brasil
}

\author{
André Carraro' \\ Isis Born Machado 2 \\ Mário Duarte Canever ${ }^{3}$ \\ José Luis Serafini Boll ${ }^{4}$
}

\section{Resumo}

Este artigo tem por objetivo apresentar uma metodologia alternativa de estimação da corrupção regional no Brasil. Sabe-se que a corrupção afeta negativamente a eficiência dos serviços públicos, e mesmo sendo um problema antigo, somente há pouco tempo têm sido aprofundados os estudos nessa área. São poucos, e muitas vezes inconsistentes os índices com dados objetivos para calcular a corrupção. Para este novo índice, utilizamos como a principal fonte de dados a base de dados do Cadastro de Responsáveis com Contas Julgadas Irregulares (Cadirreg), já que esta se fundamenta em análise multivariada, mais especificamente no método dos componentes principais. A análise deste índice torna possível identificar os estados mais, ou menos, corruptos, para, então, o governo ter possibilidade de tomar medidas preventivas a este problema. Encontramos como estados brasileiros mais corruptos Bahia, São Paulo e Maranhão; já Acre, Rondônia e Santa Catarina apresentaram os menores índices de corrupção.

Palavras-chave: Corrupção Regional. Método dos componentes principais. Economia política.

\section{Introdução}

Tendo como referência o ano da primeira divulgação dos dados do Índice de Corrupção Percebida da Transparência Internacional (ICP-TI), a linha de pesquisa em economia da corrupçáo está atingindo a sua maioridade. Desde

1 Doutor em Economia pela UFRGS. Professor Associado da UFPel. Membro docente e pesquisador do Programa de Pós-Graduação em Organizações e Mercados (PPGOM/UFPel). E-mail: andre.carraro@gmail.com

2 Mestra em Economia Aplicada pela Universidade Federal de Pelotas (UFPel). Administradora no Instituto Federal de Educação, Ciência e Tecnologia Sul-rio-grandense (IFSul). E-mail: isisbmachado@gmail.com

3 Doutor em Administração pela Wageningen University. Membro docente e pesquisador do Programa de Pós-Graduação em Organizações e Mercados (PPGOM/UFPel).E-mail: canever@ufpel.edu.br

4 Mestre em Economia pela Pontificia Universidade Católica (PUC-RS). Auditor na Controladoria Geral da União. E-mail: joseluisboll@gmail.com 
então, expandiu a pesquisa empírica na busca de determinantes e consequências para a incidência de corrupçáo em uma sociedade. A contribuição no entendimento dos fatores associados ao problema de corrupçáo ajudou no desenvolvimento de políticas anticorrupção por parte de países ou de órgãos internacionais. Por exemplo, somente o Banco Mundial auxiliou no desenvolvimento de 600 programas anticorrupçáo desde o ano de 1996 (BANERJEE; HANNA; MULLAINATHAN, 2012).

Apesar dos avanços obtidos, a linha de pesquisa em economia da corrupção possui dois grandes desafios. Em termos teóricos, os primeiros modelos econômicos (ROSE-ACKERMAN, 1975, 1978) associavam corrupção com o crime privado, seguindo a linha de argumentaçáo do modelo tradicional de crime de Becker (1968). Esses modelos estâo fortemente fundamentados em puniçóes que desencorajem a prática do crime. Em um segundo momento, esses modelos evoluíram para a aplicação do problema de moral hazard (ESKELAND; THIELE, 1999) como um caso genérico do caso de corrupção. Apesar dos avanços teóricos, esses modelos econômicos possuem os seus limites no entendimento dos diferentes conceitos de corrupção, e de sua incidência em instituiçôes distintas. Por exemplo, utilizando o conceito clássico de corrupçáo como o rompimento de uma regra para fins de um proveito privado de um agente público (JAIN, 2001), o desafio teórico está no desenvolvimento de modelos que consigam explicar o processo político de escolhas das regras que serão quebradas.

Acompanhando a evolução teórica, a mensuração da corrupção evoluiu significativamente desde as primeiras metodologias baseadas em denúncias publicadas na imprensa ${ }^{5}$. A partir da década de 1980, empresas de avaliação de risco de investimento incluíram o termo corrupçáo dentro de suas análises com a utilização da informação passada por "experts" do país 6 . No entanto, foi na década de 1990 que ocorreu a consolidaçáo da metodologia de mensuração da corrupção baseada na percepção dos participantes sobre a incidência e importância desta variável em seu país. Notadamente, o índice disponibilizado

5 Alan Doig, um pesquisador no campo da corrupção, e começou seu trabalho a partir de dados do jornalismo investigativo (SPECK, 2000).

6 Entre esses índices, o ICGR foi o que ganhou maior destaque, sendo utilizado como base de dados para o trabalho pioneiro de Mauro (1995). 
pela ONG Transparência Internacional ${ }^{7}$ (CPI-TI) ganhou espaço na mídia e tornou possível o desenvolvimento de pesquisas com base na avaliação empírica das causas e consequências da corrupção para uma sociedade.

Mais recentemente, têm crescido as críticas em relação aos indicadores de corrupçáo embasados na opiniáo, seja ela de peritos ou de cidadáos de um país. A apreciação desfavorável reside na falta de confiança na qualidade da resposta obtida pelos entrevistados. Para Golden e Picci (2005), se o indivíduo participou de relações corruptas, provavelmente ele possui incentivos para subdimensionar os casos de tal forma a não chamar a atençáo. Como a base do indicador é a percepçáo de corrupçáo, a existência de maior ou menor liberdade de imprensa, a divulgaçáo ou não de manchetes na mídia relacionadas a descobertas e a casos de corrupção ou de investigação pode, no momento da resposta, alterar a opiniáo de como o respondente percebe a corrupção. Donchev e Ujhelyi (2009) apresentam evidências de que os índices de corrupçáo percebida são sensíveis ao aumento na corrupçáo absoluta (número de casos), mas são medidas fracas para avaliar a corrupção relativa (proporção da população afetada). Por fim, os indicadores existentes informam uma medida geral que vale para todo o país. Isso pode não ser um problema para países pequenos e homogêneos, mas é um ponto importante para países grandes e com fortes diferenças regionais, como é o caso do Brasil.

Este artigo contribui para a literatura ao propor uma metodologia para a mensuração da corrupção no Brasil baseada em dados objetivos e regionais, utilizando as informaçóes disponíveis no Cadastro de Responsáveis com Contas Julgadas Irregulares (Cadirreg). A sua estimação e divulgação gera importantes consequências para a formulação de políticas públicas de combate à corrupção em um país das dimensôes do Brasil. Conhecendo-se a incidência regional de corrupção, os governantes poderáo realizar políticas públicas para os estados com maior nível de corrupção. Da mesma forma, o governo e as agências de fiscalização poderão focar os seus esforços em regiôes mais problemáticas, aumentando a eficiência da fiscalização e do controle da corrupção no país.

7 Para maiores informações, ver Transparência Internacional, disponivel em: <http://www.transparency.org>. 


\section{Conceitos e mensuração de corrupção}

A Corrupção, devido à sua complexidade, tem relação com vários fatores, tanto em suas causas como em suas consequências. Por conta disso, o termo corrupção faz parte de um conjunto de fenômenos, que são compreendidos por todos; mas, que quando se solicita uma definiçáo à populaçáa, esta encontra dificuldade de conceituar o termo (BREI, 1996).

E essa dificuldade não é exclusiva da sociedade. A literatura econômica também enfrenta dificuldades em avaliar os conceitos que envolvem o termo corrupção. Praticamente em todos os conceitos, explícita ou implicitamente, existe a ideia de poder discricionário por parte do representante do governo; no entanto, a ação de um burocrata pode gerar benefícios sem que isso esteja relacionado à corrupção ${ }^{8}$. Da mesma forma, a legislação pública pode prover o poder discricionário, sem que seu uso implique transaçóes corruptas. Apesar da dificuldade de identificar o que é um comportamento corrupto, uma das definiçóes clássicas caracteriza corrupção como o uso do poder público em benefício próprio (TRANSPARÊNCIA INTERNACIONAL, 2011). E essa definição, apesar de ampla, tem a virtude de separar o crime público do crime privado ao exigir a presença de um representante do setor público como requisito para se caracterizar uma transaçáo como sendo corrupta.

A partir do conceito geral de corrupção, a literatura sobre o tema definiu novos conceitos específicos para designar transaçóes com características mais específicas entre si; entre eles, destacam-se: corrupção burocrática, corrupção legislativa e corrupção governamental.

A tipologia pioneira dentro da economia política da corrupção foi a corrupçáo burocrática. Nela, está presente a figura de um burocrata que possui o poder de alocar a oferta de um bem ou serviço público. Ao perceber ser monopolista da oferta e de possuir o poder discricionário para definir quem receberá ou não o bem público, esse burocrata racionalmente decide vender o bem público, demandando uma propina. Esse tipo de corrupção tem sua explicação teórica mais associada à estrutura de mercado do governo (SHLEIFER; VISHNY, 1993), pois o monopólio e o poder discricionário

8 Um exemplo disso é quando um burocrata recebe um presente pela presteza ou gentileza de seu atendimento (ver TRANSPARENCIA INTERNACIONAL, 20II). 
geram os incentivos e as oportunidades para o burocrata decidir racionalmente ser corrupto. Outro modelo teórico usual na análise da corrupção burocrática é a teoria do agente-principal (ROSE-ACKERMAN, 1978). Nesses modelos, o burocrata (ou as agências governamentais) representa o agente, e o governo central é representado pelo principal. Com base nesse modelo teórico, diversas pesquisas foram realizadas com o objetivo de analisar o impacto do processo de fiscalização e da descentralização dos recursos públicos sobre a intensidade da corrupção (BAC, 1996; CHAND; MOENE, 1999).

Uma segunda tipologia de corrupçáo envolve as peculiaridades da corrupçáo política baseada nos estudos da Teoria da Escolha Pública (BUCHANAN; TULLOCK, 1962). De uma forma geral, esses modelos estão focados na corrupção que possui origem no financiamento de campanhas políticas (BRONARS, 1997). Um dos pressupostos é que o desempenho econômico das empresas e o desempenho político dos candidatos estáo interligados pelo processo eleitoral (PERSSON; TABELLINI, 2003). Assim, políticos e empresários são tratados como agentes maximizadores de interesses próprios que se encontram no mercado político para atender a suas necessidades. De um lado, há políticos em campanha que necessitam de recursos financeiros para maximizar a probabilidade de serem eleitos; de outro, empresários desejam maximizar seus lucros por meio da atuação de políticos eleitos que realizam políticas públicas em prol de seus objetivos (MITCHELL; SIMMONS, 2003). Esse tipo de corrupção inclui a compra de votos, visto que o legislador tem o intuito de se reeleger ou, ainda, envolve o fato de funcionários públicos, valendo-se de seus cargos executivos, "obrigarem" uma aprovaçáo de lei (ROSE-ACKERMAN, 1999).

O Código Penal brasileiro caracteriza os crimes de corrupção governamental, os quais podem assumir duas formas: crimes praticados por funcionário público contra a administração em geral e, crimes praticados por particular contra a administração em geral. Entre os crimes praticados por funcionários públicos contra a Administraçáo Pública, destacam-se o crime de peculato e corrupção passiva. O peculato é um exemplo de corrupção governamental. $\mathrm{O}$ art. 312 do Código Penal define o crime como sendo um crime cometido por funcionário público contra a Administração Pública, ou seja, é um que somente pode ser cometido por servidor público. É previsto em três modalidades diferentes: peculato-apropriação, peculato-desvio e peculato-furto. Segundo o Código Penal: 
Art. 312 - Apropriar-se o funcionário público de dinheiro, valor ou qualquer outro bem móvel, público ou particular, de que tem a posse em razão do cargo, ou desviá-lo, em proveito próprio ou alheio:

Pena - reclusão, de 2 (dois) a 12 (doze) anos, e multa.

$\S 1^{\circ}$ - Aplica-se a mesma pena, se o funcionário público, embora não tendo a posse do dinheiro, valor ou bem, o subtrai, ou concorre para que seja subtraído, em proveito próprio ou alheio, valendo-se de facilidade que lhe proporciona a qualidade de funcionário. (BRASIL, 20I2)

Por esse motivo, neste estudo o conceito mais adequado é o de corrupção governamental; afinal, nesse conceito, o foco está na quebra de uma regra formal que ocorre quando os agentes públicos envolvidos rompem os códigos de conduta que regulamentam sua atuação no setor público para obterem ilicitamente a sua recompensa financeira com o desvio de recursos públicos. Para Johnson (1975), a corrupção governamental se refere ao desvio das receitas governamentais e do fluxo de renda nacional para aumentar a riqueza privada de membros do governo, quando a estes náo é conferido esse direito.

Sendo assim, é a quebra da regra que irá definir a transação como sendo corrupta ou não (BANERJEE; HANNA; MULLAINATHAN, 2012). Essa estratégia é útil, pois permite avaliar tanto a corrupção política quanto a corrupção burocrática e, ao mesmo tempo, é mais apropriada a mensuraçóes de corrupção apoiadas em informaçóes objetivas já que ela está baseada em julgamentos subjetivos. Ressalta-se que não é do conhecimento dos autores a publicação de outros artigos que utilizam os dados objetivos do Cadirreg para o Brasil.

\section{Mensurando a corrupção}

Como um mecanismo sistemático de mensuração da corrupção, a atuação das agências de risco pode ser vista como um marco inicial na mensuração da corrupção entre países. $\mathrm{O}$ interessante é que a preocupação com o problema da corrupção teria se manifestado de forma pioneira por parte dos empresários, que - em busca de avaliação sobre a segurança jurídica, institucional e econômica de países com potencial para atrair investidores - passou a demandar uma avaliação quanto à qualidade do governo.

Com o objetivo de atender a essa demanda, as empresas de risco incorporaram, em seus relatórios de avaliação, uma proxy para a incidência de corrupção envolvendo o risco político. Nessa linha de indicadores, o Internal 
Capital Generation Rate (ICGR) ganhou destaque, e foi utilizado como fonte de dados sobre corrupção pelos trabalhos pioneiros de estimação empírica da corrupção no crescimento econômico (MAURO, 1995). No entanto, o propósito dessa metodologia é medir o risco de um país, no qual o item corrupção faz parte da análise de um fator chamado risco político. O propósito desse indicador não é mensurar a corrupção, mas avaliar de que forma a sua existência coloca em risco a realização de um investimento em um determinado país.

A aparição do Índice de Corrupção Percebida (ICP-TI) avaliado pela Transparência Internacional, no início dos anos 1990, alterou substancialmente a forma de avaliaçáo da corrupçáo entre países. A disponibilidade de um índice padrão com uma nota quantitativa para a existência de corrupçáo, para uma amostra relativamente grande de países, permitiu a ampliação de trabalhos empíricos de estimaçáo das causas e das consequências da corrupçáo usando estimativas econométricas do tipo cross-section e, posteriormente, de dados de painel (MAURO, 1997; TREISMAN, 2000; ANDERSON; TVERDOVA, 2003; TANZI; DAVOODI, 1997). Por meio dessa metodologia, o problema da corrupçáo se tornou popular, amplamente discutido no meio político e serviu de base para diversos programas de combate a esse problema.

A estratégia de mensuração da corrupção do ICP-TI está na percepção da incidência de corrupção reportada por especialistas. Para isso, utiliza fontes de informação de diferentes instituições. Por exemplo, para o ano de 2012 foram utilizadas 14 fontes diferentes de informação (PARUOLO; SAISANA; SALTELLI, 2012). Um determinando país, para ser avaliado, precisa ter a disponibilidade de pelo menos três fontes de informação. Como destacado por June (2008), em comum essas diferentes fontes de informação utilizam expressóes como democracia, transparência, fiscalizaçáo e governança. Assim como é com relação à corrupção, esse conjunto de expressôes refletem conceitos abrangentes e de difícil mensuração.

Apesar de sua ampla utilização, uma literatura mais recente tem questionado a qualidade da informaçáo passada pelos indicadores de corrupçáo fundados em percepçáo. A maior dificuldade enfrentada por essa metodologia está na incerteza da capacidade de um cidadáo em capturar, de forma adequada, a corrupçáo corrente.

Svensson (2005) e Treisman (2007) estão entre os primeiros pesquisadores a chamar a atenção para a possibilidade de estimativas viesadas por parte 
dos indicadores fundamentados na percepção da corrupção. Uma resposta imediata para tentar corrigir um possível viés dessa metodologia seria utilizar a opinião de especialistas em avaliação de governos. Kaufmann, Kraay e Mastruzzi (2008) fornecem uma ampla análise dos limites existentes. Para eles, a opiniáo de especialistas ligados ao mercado empresarial reflete muito o ponto de vista empresarial, enquanto a opinião de avaliadores políticos está fortemente ligada à sua própria percepçáo de ideal político. Dessa forma, tanto um como outro gerariam estimativas viesadas.

Olken (2009) examina a dificuldade na percepção de corrupção a partir de um experimento realizado em distritos da Indonésia. O experimento comparou os valores gastos na construção de estradas pelo governo distrital com os valores estimados por engenheiros independentes. Um dos seus principais resultados é que o aumento em $10 \%$ nos gastos da construção por parte do governo aumenta a probabilidade da população reportar corrupção em apenas 0,8\%. Banerjee e Pande (2007) estimaram a corrupçáo política a partir de entrevistas com jornalistas que estão cobrindo eleições locais na Índia. Após as eleiçôes, eles compararam a percepção dos jornalistas com indicadores objetivos de crime eleitoral e identificaram a presença de viés de percepção.

Por outro lado, grande parte dos indicadores de corrupção está baseada em dados nacionais. A consequência disso é que pouco se sabe sobre a incidência regional de corrupçáo. Implicitamente, o que está sendo utilizado é a premissa de que as diferentes regióes são homogêneas em relação à distribuição espacial da corrupçáo. Aos poucos, a linha de pesquisa em economia da corrupção tem dedicado esforços para avaliar a incidência de corrupção regional. Em termos mundiais, existem duas linhas com propostas de metodologias alternativas para mensurar corrupção regional. Na primeira, contemplam-se os estudos de Del Monte e Papagni (2001) e de Liu e Lin (2012) que utilizam dados de crimes cometidos contra o patrimônio público. Golden e Picci (2005) e Hite (2006) utilizam o conceito de ineficiência do retorno do investimento do gasto público em infraestrutura como um conceito que se aproxima da corrupção regional.

A proposta apresentada nesse artigo se aproxima da linha de pesquisa de avaliar corrupçáo regional por meio do resultado de fiscalizaçóes. Diferentemente da estratégia adotada por Del Monte e Papagni (2001) e Liu e Lin (2012), não será utilizada uma quantidade de processos irregulares per capita, 
pois serão avaliados os valores monetários envolvidos nos processos considerados irregulares.

\section{Utilização do Cadirreg como informação de corrupção}

A aprovação da Constituição brasileira de 1988 garantiu um aumento considerável de transferência de recursos do governo central para os demais entes federativos. Em contrapartida, estados e municípios assumiram maiores responsabilidades na oferta de bens e serviços públicos. $\mathrm{O}$ argumento teórico para a descentralização dos recursos estava no aumento da eficiência nos gastos públicos, gerado pela possibilidade de haver maior controle e fiscalização do eleitor mais próximo do gestor local.

No entanto, além da fiscalização do eleitor, a Constituição não previa mecanismos formais para garantir que os recursos públicos seriam utilizados de forma apropriada, o que acabou aumentando o risco de corrupção envolvendo recursos que saíam do cofre federal e iriam para o cofre de estados e municípios.

Esse acréscimo de risco já estava previsto nos modelos econômicos de corrupção (SHLEIFER; VISHNY, 1993), considerando-se que o aumento do número de agências governamentais envolvidas na coordenação dos recursos públicos poderia levar a uma elevação na extração de renda por parte da burocracia envolvida no processo, o que acarretaria uma reduçáo do investimento e, consequentemente, redução no crescimento econômico. Nessa mesma linha, a Teoria dos Contratos de Hart e Moore (1988) reforça a percepção de que a criação de transferências intergovernamentais, sem a existência dos mecanismos legais que criem os limites, para que os agentes públicos envolvidos no processo de transferência possam adotar comportamentos oportunistas, elevam os problemas de agente-principal, gerando alocaçóes ineficientes.

Uma das iniciativas para criar mecanismos de garantia do uso adequado de recursos públicos foi a criação, no ano de 2001, da Controladoria Geral da Uniāog (CGU), com o objetivo declarado de combater os casos de fraude

9 Para maiores informações, acesse o site da Controladoria Geral da União, disponível em: <http://www.cgu. gou.br/>. 
e de corrupção que envolviam recursos públicos federais. A partir daí, todos os programas e projetos que se relacionem a recursos públicos federais são auditados na busca de irregularidades.

Brollo (2008) e Ferraz, Finan e Moreira (2008) utilizam dados gerados por auditorias aleatórias da CGU como estratégia empírica para reportar corrupçáo com menor risco de existência de oportunismo por parte dos auditores e burocratas locais. Basicamente, por meio dessa amostra aleatória, são sorteados os municípios; e estes, que após visita dos auditores, receberáo um relatório que poderá reportar irregularidades.

Nesse artigo, utiliza-se uma diferente estratégia: os dados existentes no Cadastro de Contas Irregulares do Tribunal de Contas da União (Cadirreg) sáo utilizados. Esse cadastro é composto por todos os casos cujos auditores encontraram algum tipo de irregularidade, e após investigaçáo por parte do Tribunal de Contas da União (TCU) foram julgadas irregulares. Essa opçáo peca por não utilizar dados originados por um processo aleatório de auditoria, o qual, portanto, pode estar afetado pela existência de comportamento oportunista entre auditores e burocratas locais. No entanto, esse processo tem a virtude de somente incluir casos julgados irregulares, ao contrário da estratégia anterior que utiliza dados reportados como irregularidades, mas que ainda não foram julgados.

Para entender melhor a base de dados do Cadirreg, é necessário entender a atuação do Tribunal de Contas da Uniáo, sendo que suas atribuiçôes estão descritas na Constituição Federal do Brasil de 1988, em seu art. 71 (BRASIL, 1988). De acordo com o TCU (2013), as contas apresentadas sáo analisadas, sob os aspectos de legalidade, legitimidade, economicidade, eficiência e eficácia; após sua apreciação, são julgadas:

- regulares, quando, de forma clara e objetiva, expressam a legalidade, a legitimidade e a economicidade dos atos de gestáo do responsável;

- regulares com ressalvas, quando detectada a existência de impropriedades ou de faltas de natureza formal que não resultem em danos ao erário;

- irregulares, quando comprovada qualquer das seguintes ocorrências: a omissão no dever de prestar contas, a prática de ato de gestão ilegal, 
ilegítimo, antieconômico, desfalque ou desvio de dinheiros, bens e valores públicos.

- iliquidáveis, quando for impossível o julgamento de mérito.

Todas as contas julgadas irregulares encontram-se no Cadirreg. Essas contas irregulares podem sofrer penalidades como multa ou multa e recolhimento do valor do débito apurado. Além disso, quando o banco de dados foi analisado, retiraram-se todos os casos que envolviam irregularidades cometidas por burocratas, mas que não geravam prejuízo para o ente público. Assim, foram descartados os casos que envolviam erros de boa-fé, restando apenas os casos julgados e condenados por prejuízo ao erário público, além de serem excluídos, também, os débitos solidários e as multas, já que essas têm caráter punitivo. Para a maioria dos processos que constam na base de dados, existe, em média, a defasagem de um ano entre o fato que deu origem a aqueles e a sua formalização. Por isso, essa defasagem foi levada em consideração nos valores anuais. Acredita-se que os dados que compóem o banco do Cadirreg estão mais próximos do conceito de corrupção.

\section{Metodologia}

A metodologia prevista para a construçáo do indicador de corrupção governamental está baseada em análise multivariada, mais especificamente no método dos componentes principais. De acordo com Abdi e Williams (2010), essa é uma técnica multivariada, também conhecida como "transformada de Hotelling", que analisa uma tabela de dados em que as observaçóes são descritas por várias intercorrelaçóes das variáveis quantitativas dependentes.

Esse método tem por objetivo obter combinaçóes lineares de um conjunto de variáveis que possam reter, das variáveis originais, o máximo possível de informaçôes contidas nestas. Luna (2006) afirma que a ideia básica é gerar um novo conjunto de variáveis que são combinaçôes lineares do conjunto original e, ortogonais entre si. A partir de pesos diferentes para cada uma das variáveis explicativas do modelo, são obtidas as variáveis transformadas - chamadas de componentes principais ou fatores.

De uma forma geral, a análise dos componentes principais consiste em promover uma transformaçáo linear nos dados de modo que os dados resultantes dessa transformação tenham seus componentes mais relevantes nas 
primeiras dimensôes, em eixos denominados principais. A matriz de transformação utilizada para o cálculo consiste em uma matriz cujas colunas são os autovetores da matriz de covariância estimada dos dados. As figuras a seguir ilustram um conjunto com 100 pontos bidimensionais gerados sinteticamente pelo MATLAB e o mesmo conjunto após a aplicação da análise dos componentes principais.

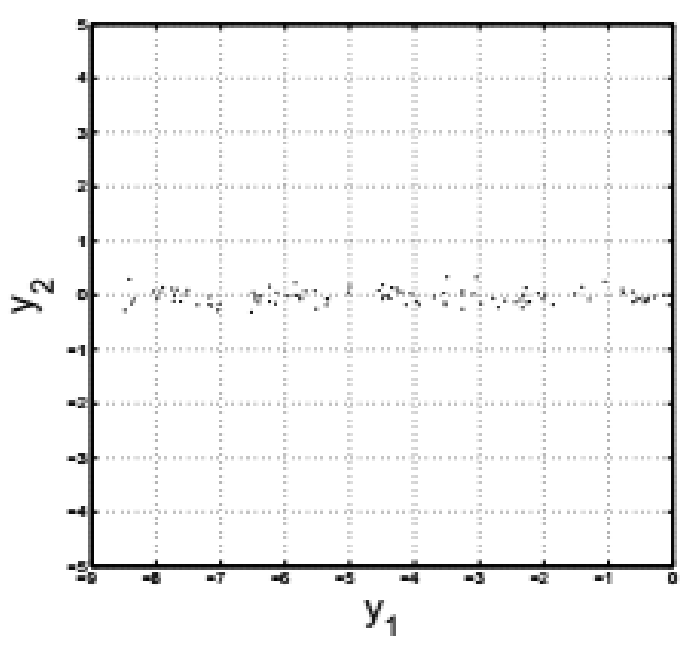

Figura I - Conjunto de Dados

Fonte: Elaborada pelos autores.

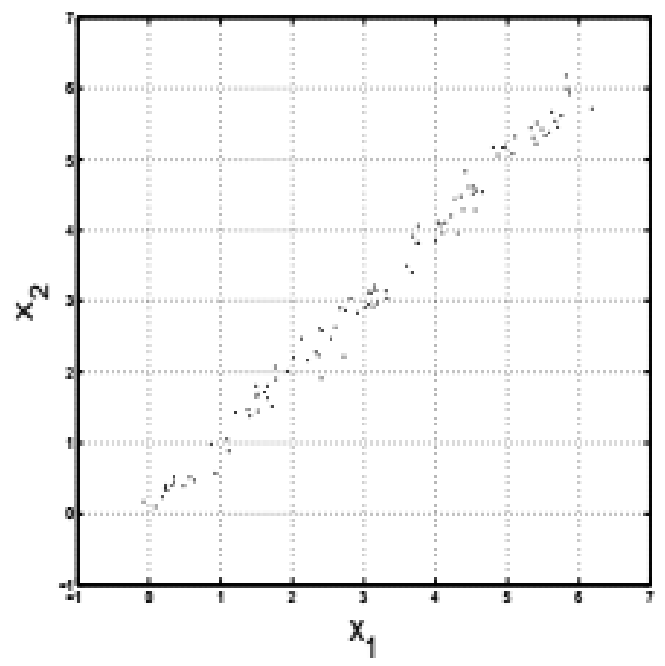

Figura 2 - Conjunto de dados após análise dos componentes principais

Fonte: Elaborada pelos autores. 
Os componentes principais são os vetores da matriz de covariância. O primeiro componente principal é o vetor associado ao valor mais elevado. O segundo componente principal é o vetor correspondente ao segundo valor mais elevado, e assim por diante. A rotaçáo dos fatores permite encontrar uma matriz de pesos mais facilmente interpretável. Sendo que eles são extraídos sempre na ordem do mais explicativo para o menos explicativo e, seus componentes serão sempre no mesmo número de suas variáveis.

Parte-se de uma matriz de dados de ordem " $\mathrm{x}$ p", normalmente denominada de matriz "X".

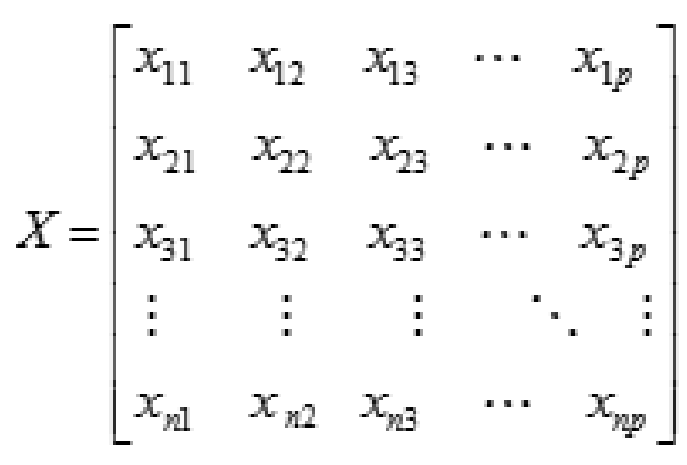

Considerando o vetor $\mathrm{X}^{\mathrm{t}}=\left[\mathrm{X}_{\mathrm{i} 1} \mathrm{X}_{\mathrm{i} 2} \mathrm{X}_{\mathrm{i} 3} \ldots \mathrm{X}_{\mathrm{ip}}\right]$ constituído por " $\mathrm{p}$ " componentes, onde p é uma variável aleatória e possui: autovalores $\lambda_{1} \geq \lambda_{2} \geq \lambda_{3} \geq \ldots \geq$ $\lambda_{\mathrm{p}} \geq 0$, autovetores normalizados $e_{1}, e_{2}, e_{3}, \ldots e_{p}$, vetor de médias $(\mu)$ e matriz de covariância $\left(\sum_{\mathrm{pxp}}\right)$ dados por:

$$
\mu=\mathrm{E}(\mathrm{X})=\left[\begin{array}{c}
\mu_{1} \\
\mu_{2} \\
\cdots \\
\mu_{p}
\end{array}\right] \quad \mathrm{e} \sum_{\mathrm{pxp}}=\operatorname{Cov}\left(\mathrm{X}_{\mathrm{i}}, \mathrm{X}_{\mathrm{j}}\right)=\left[\begin{array}{cccc}
\sigma_{11} & \sigma_{12} & \cdots & \sigma_{1 p} \\
\sigma_{21} & \sigma_{22} & \cdots & \sigma_{2 p} \\
\vdots & \vdots & \ddots & \vdots \\
\sigma_{p 1} & \sigma_{p 2} & \cdots & \sigma_{p p}
\end{array}\right]
$$

$A \operatorname{Cov}\left(X_{i}, X_{j}\right)=\sigma_{i j}=E\left[\left(X_{i}-\mu_{i}\right)\left(X_{j}-\mu_{j}\right)\right]$ sendo que $i, j=1,2,3, \ldots, p$. Quando $i=j$ a covariância corresponde a variância da variável $X_{i} i=1,2,3, \ldots, p$.

Os autovalores e os autovetores seguem as pressuposiçóes:

a) $e_{i}, e_{j}=0$ para todo $\mathrm{i} \neq \mathrm{j}$;

b) $e_{i} e_{j}=1$ para todo $\mathrm{i}=\mathrm{j}$; 
c) $\sum_{\text {pxp }} e_{i}=\lambda_{\mathrm{i}} e_{i}$, para todo $\mathrm{i}=1,2,3, \ldots, \mathrm{p}$;

Considerando que o componente principal da i-ésima variável é representado por $Y_{\mathrm{i}}$, é definido da seguinte maneira:

$$
Y_{i}=e_{i}^{\prime} X=e_{i 1} X_{1}+e_{i 2} X_{2}+e_{i 3} X_{3}+\ldots+e_{i p} X_{p}
$$

Além disso, a covariância entre quaisquer duas componentes deve ser nula, ou seja, $\operatorname{Cov}\left[Y_{i}, Y_{j}\right]=0, i \neq j \operatorname{com} i, j=1,2, \ldots, p$.

Uma discrepância entre a variância das variáveis $\mathrm{X}_{\mathrm{i}}$ ocorre quando os componentes principais obtidos são influenciados em grande parte pelas variáveis de maior variância. Assim, a aplicaçáo do procedimento pode levar a conclusóes equivocadas. A medida tomada para controlar esse problema nas variáveis foi padronizar as variáveis, colocando os dados originais em uma mesma escala de medidas. Isso foi possível padronizando cada uma das variáveis pela sua média e desvio padrão. Para normalizar as variáveis, utiliza-se: $Z_{i}=\frac{X_{i}-\mu_{i}}{\sigma_{i}}$, onde representa a média de $X_{i}$ e $\sigma_{i}$ representa o desvio padráo.

Portanto, utiliza-se a matriz de correlação $\mathrm{R}_{\mathrm{pxp}}$ ao invés da matriz de covariância $\sum_{\text {pxp, }}$ onde:

$$
R_{p x p}=\left[\begin{array}{cccc}
1 & \rho_{12} & \cdots & \rho_{1 p} \\
\rho_{21} & 1 & \cdots & \rho_{2 p} \\
\vdots & \vdots & \ddots & \vdots \\
\rho_{p 1} & \rho_{p 2} & \cdots & 1
\end{array}\right]
$$

sendo $\rho$ o coeficiente de correlaçáo definido por: $\rho_{i j}=\frac{\sigma_{i j}}{\sigma_{i} \sigma_{j}}, i, j=1,2,3, \ldots$, p.

Então, a i-ésima componente estimada $Y_{i}$ pela matriz de correlação é definida pela expressão:

$$
Y_{i}=e_{i 1} Z_{1}+e_{i 2} Z_{2}+e_{i 3} Z_{3}+\ldots e_{i p} Z_{p}
$$

Esse método se apresenta como uma alternativa adequada de estimação, pois separa a informação relevante da informaçáo redundante e aleatória. A finalidade da análise é utilizar variáveis que possuem uma correlação com 
corrupção e, então, encontrar combinações destas para produzir índices que sejam não correlacionados na ordem de sua importância e que representem a variação nos dados.

\section{Variáveis e procedimento}

A base do modelo é a construção de um indicador composto de corrupção objetiva que foi elaborado com as seguintes variáveis 10 não deflacionadas:

Tabela I - Descrição das Variáveis

\begin{tabular}{|c|c|c|c|}
\hline Variável & Descrição & Fonte & Unidade de medida \\
\hline LOA & $\begin{array}{l}\text { A Lei Orçamentária Anual é uma } \\
\text { lei elaborada pelo Poder Executivo } \\
\text { que autoriza as despesas do } \\
\text { Governo de acordo com a previsão } \\
\text { de arrecadação. Ela contém as } \\
\text { despesas anuais da União; por isso, } \\
\text { é considerada a origem dos débitos } \\
\text { irregulares cadastrados no Cadirreg }\end{array}$ & $\begin{array}{l}\text { Portal da } \\
\text { Câmara dos } \\
\text { Deputados }\end{array}$ & Reais \\
\hline CADIRREG & $\begin{array}{l}\text { Valor dos processos julgados } \\
\text { irregulares do Cadirreg }\end{array}$ & $\begin{array}{l}\text { Tribunal de } \\
\text { Contas da } \\
\text { União }\end{array}$ & Reais \\
\hline QUAANTIDADE & $\begin{array}{l}\text { Quantidade de processos julgados } \\
\text { irregulares do Cadirreg }\end{array}$ & $\begin{array}{l}\text { Tribunal de } \\
\text { Contas da } \\
\text { União }\end{array}$ & Unidades \\
\hline $\begin{array}{l}\text { VPROC/ } \\
\text { VTOTAL }\end{array}$ & $\begin{array}{l}\text { Participação de cada estado no } \\
\text { valor total dos processos julgados } \\
\text { irregulares do Cadirreg }\end{array}$ & $\begin{array}{l}\text { Tribunal de } \\
\text { Contas da } \\
\text { União }\end{array}$ & Porcentagem \\
\hline $\begin{array}{l}\text { NO PROC./ } \\
\text { NO TOTAL }\end{array}$ & $\begin{array}{l}\text { Participação de cada estado na } \\
\text { quantidade de processos julgados } \\
\text { irregulares do Cadirreg }\end{array}$ & $\begin{array}{l}\text { Tribunal de } \\
\text { Contas da } \\
\text { União }\end{array}$ & Porcentagem \\
\hline
\end{tabular}

Fonte: Elaborada pelos autores.

Cada uma dessas variáveis influencia de forma direta ou indireta o nível de corrupção. A Lei Orçamentária Anual (LOA) é um instrumento de gestão,

10 Outras variáveis foram testadas e excluidas do modelo devido à alta correlação entre elas. São elas: Valor Médio e Porcentagem do valor do Cadirreg sobre a Lei Orçamentária Anual. 
com ênfase nos aspectos financeiros e físicos, compatível com a Lei de Diretrizes Orçamentárias (LDO) e com o Plano Plurianual (PPA), pois estima a receita e fixa a despesa para o período de um ano, visando a atingir objetivos preestabelecidos da política governamental. Com isso, ela é considerada a origem das contas julgadas irregulares. Já o número de processos do Cadirreg e os seus valores são a principal fonte de dados do estudo, já que eles se reportam à corrupção.

Esses dados serão base para as variáveis que farão parte do conjunto avaliado pelo método dos componentes principais, de tal forma a gerar a ponderação para sua participação no índice.

Depois de analisada a correlação entre as variáveis que foram usadas, verificou-se o melhor ajuste dos dados por meio de valores ou quantidades. Para o período analisado, a maior parte dos anos apresentou um único fator de ajuste via valores. Travou-se em um fator para cada ano, e foi feita a padronizaçáo de todas as variáveis, para, somente depois, utilizar o método dos componentes principais. Com os dados disponíveis, o Índice Corrupçáo Estadual (ICE) foi gerado usando os valores de cada estado para o período de 1998 a 2008, como é ilustrado a seguir:

$$
\begin{aligned}
& I C E_{i}=\beta_{i 0}+\beta_{i 1} V L O A_{-} P A D_{t}+\beta_{i 2} \frac{N^{o} P R O C_{t}}{N^{o} T O T A L_{-} P A D_{t}}+\beta_{i 3} \frac{V P R O C_{t}}{V_{T O T A L} P A D_{t}} \\
& +\beta_{i 4} \text { CADIRREG_PAD }+\beta_{i 5} \text { QUANTIDADE_PAD }
\end{aligned}
$$

Sendo:

VLOA_PAD = Valor da Lei Orçamentária Anual padronizada .

No PROC/No TOTAL_PAD = Porcentagem da participação do estado na quantidade de Processos do Cadastro de Contas Irregulares do Tribunal de Contas da União padronizada.

VPROC/VTOTAL_PAD = Porcentagem da participaçáo do estado no valor total dos Processos do Cadastro de Contas Irregulares do Tribunal de Contas da Uniáo padronizada. 
CADIRREG_PAD = Valor dos Processos do Cadastro de Contas Irregulares do Tribunal de Contas da Uniáo padronizado.

QUANTIDADE_PAD = Número de Processos do Cadastro de Contas Irregulares do Tribunal de Contas da União padronizado.

Os resultados obtidos do $\mathrm{ICE}^{1}$ estão expostos no Anexo 2. Em seguida, calculou-se a média do período para analisar os estados mais e menos corruptos nesse intervalo de tempo (1998-2008). O ICE foi calculado novamente dentro de uma medida de escala entre zero e um, e está apresentado na Tabela 2.

$\mathrm{Na}$ tabela apresentada a seguir, consideram-se os estados mais corruptos com o valor um, enquanto os menos corruptos recebem o valor zero. Os demais estados recebem valores intermediários. Para isso, considera-se que:

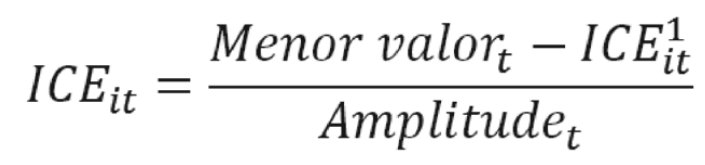


Tabela 2 - Índice Corrupção Estadual para o período de 1998 a 2008

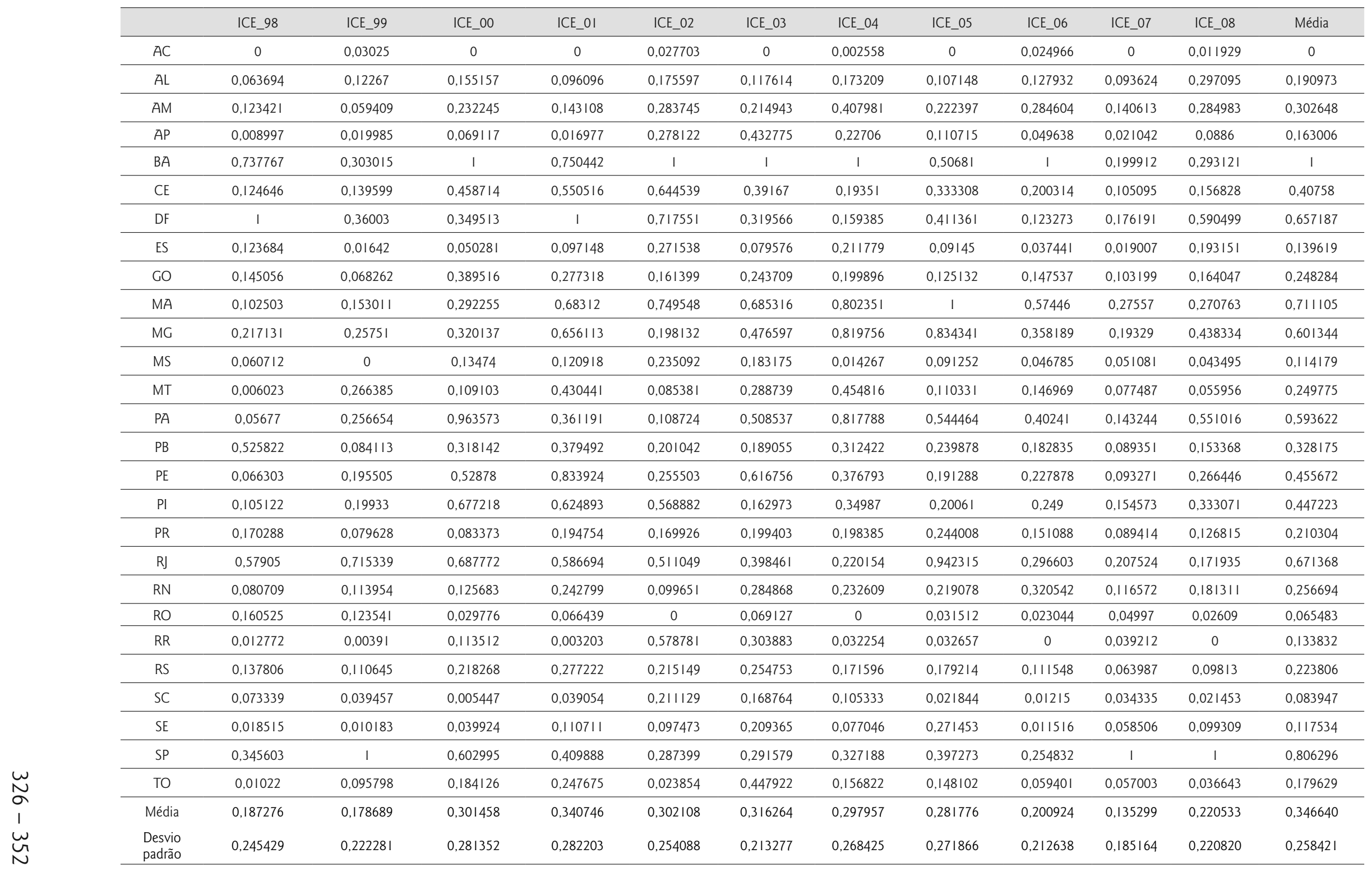




\section{Resultados}

Os resultados obtidos no indicador estadual de corrupção indicam que existe uma diferença entre os estados brasileiros. Com os resultados obtidos para a média do período analisado, pode-se notar que os três estados mais corruptos são respectivamente, Bahia, São Paulo e Maranhão. Já ao analisar os estados menos corruptos encontram-se, respectivamente, Acre, Rondônia e Santa Catarina. Entretanto, esses dados não analisam a eficiência institucional de cada estado, ou seja, alguns estados podem ser considerados mais corruptos devido a diferenças na eficiência de fiscalização.

Ainda considerando o resultado da Tabela 2, observa-se que o desvio padrão anual entre os estados não apresenta altas variações enquanto a média possui uma discrepância maior entre os anos analisados. O estado da Bahia que foi considerado o mais corrupto na média, foi o mais corrupto na metade dos anos analisados, ou seja, em cinco anos obteve o maior índice. $\mathrm{O}$ estado menos corrupto, o Acre, foi o que obteve o menor índice em seis anos dos dez anos analisados.

Na Figura 3, apresenta-se a classificação por estados brasileiros a partir da distribuição em quartis da média obtida em cada estado no período analisado.

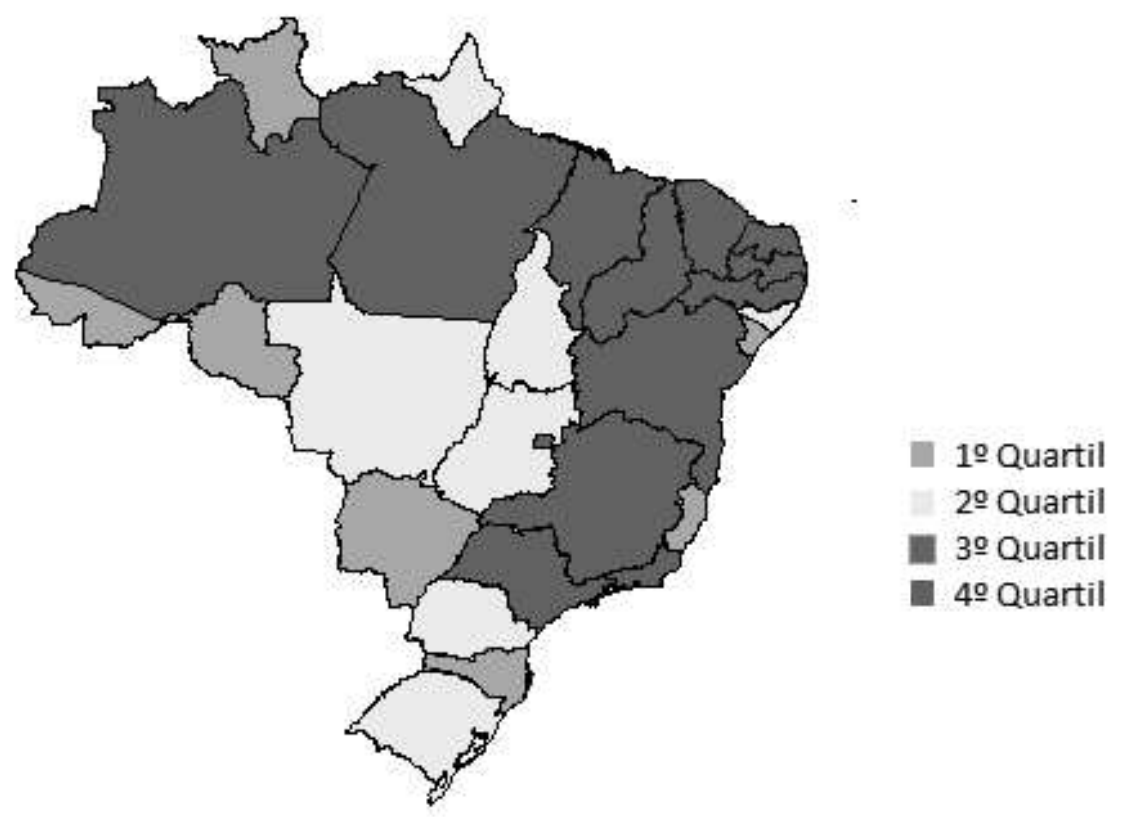

Figura 3 - Divisão de quartil da média dos índices de corrupção estadual no período de 1998 a 2008

Fonte: Elaborada pelos autores. 
Os estados apresentados na Figura 3 com tons azuis representam os 50\% dos estados menos corruptos, enquanto os com tons avermelhados são os outros 50\% mais corruptos. Nota-se que os estados que estâo entre os $25 \%$ mais corruptos ( $4^{\circ}$ quartil) estáo situados entre as regióes sudeste, nordeste e norte, além do Distrito Federal. Já as regióes sul e centro-oeste, estão entre os 50\% menos corruptos do período.

Focando a atenção apenas nas médias obtidas, a regiáo Nordeste, que possui menor renda per capita média, destaca-se com os maiores indicadores de corrupção calculados. Todavia a região sudeste, onde encontramos o estado de São Paulo, também pertence às regióes mais corruptas, embora tenha uma das maiores rendas per capita do país.

Destaca-se, também, a região Sul do país, que, assim como São Paulo, possui uma das maiores médias de renda per capita, mas apresenta os menores indicadores de corrupção, considerando-se as médias calculadas. Para que essas associaçóes sejam compreendidas, seria interessante realizar um estudo sobre os determinantes dessa corrupção a partir desse índice, avaliando, também, a qualidade institucional de cada estado.

\section{Considerações Finais}

O objetivo deste estudo consiste em apresentar uma proposta para estimar-se a corrupçáo regional. A principal variável se refere às contas julgadas irregulares pelo Tribunal de Contas da União, onde se encontram os valores e os números de processos que refletem a corrupção. Os resultados encontrados refletem a heterogeneidade existente na incidência de corrupçáo entre os estados brasileiros. Destaca-se a importância de um indicador regional que permite avaliar essas diferenças entre as diversas partes do território brasileiro.

Sabendo do efeito negativo que a corrupção causa no Brasil, este artigo traz uma contribuiçáo importante para o estudo desse problema. Até entáo, o único índice divulgado anualmente em nosso país é o da Transparência Internacional, que divulga um índice nacional.

Do ponto de vista de políticas públicas, a compreensão de que o fenômeno de corrupção não é homogêneo dentro do país pode auxiliar a Administração Pública desenvolver políticas focadas ao combate à corrupçáo. Sabe-se das dificuldades do Governo Federal em fiscalizar de forma adequada todos os 
programas e projetos que envolvem transferência de recursos públicos; desse modo, esta pesquisa pode auxiliar na focalização da aplicação de recursos e a aumentar os esforços no combate à corrupção.

A partir da disponibilidade de informaçóes regionais, pode-se avançar nos estudos empíricos acerca da corrupção regional com a avaliaçáo de fatores econômicos, políticos e sociais associados aos resultados obtidos e a respeito dos efeitos da corrupçáo regional para o desenvolvimento econômico dos estados brasileiros. Para uma nova agenda de pesquisa, deve-se testar a robustez dos resultados sempre considerando as diferenças institucionais.

\section{Referências}

ABDI. H.; WILliaMS, L. J. Principal Component Analysis. Computational Statistics, v. 2, p. 433-459, 2010.

ANDERSON, C. J.; TVERDOVA, Y. V. Corruption, political allegiances, and attitudes toward government in contemporary democracies. American Journal of Political Science, v. 47, n. 1, p. 91-109, 2003.

BAC, M. Corruption and Supervision Costs in Hierarchies. Journal of Comparative Economics, v. 22, p. 99-118, 1996.

BANERJEE, A. V.; PANDE, R. Parochial Politics Ethnic Preferences and Politician Corruption. Faculty Research Working Paper Series, n. RWP07-031, p. 1-49, 2007. Disponível em: <https:// research.hks.harvard.edu/publications/workingpapers/citation.aspx?PubId=4877\&type=WPN>. Acesso em: 10 ago. 2013

.; HANNA, R.; MULLAINATHAN, S. C. Corruption. National Bureau of Economic Research, Working Paper 17968, 75 p., 2012.

BECKER, G. Crime and Punishment: an economics approach. The Journal of Political Economy, v. 76, n. 2, p. 169-217, 1968.

BRASIL. Constituição (1988). Constituiçáo da República Federativa do Brasil. Brasília, DF: Senado Federal: Centro Gráfico, 1988.

BRASIL. Presidência da República. Casa Civil. Subchefia para Assuntos Jurídicos. Decreto-Lei no 2.848, de 7 de dezembro de 1940. Código Penal. 07/12/1940 DOU de 31.12.1940 e retificado em 3.1.1941 http://www.planalto.gov.br/ccivil_03/decreto-lei/Del2848.htm

BREI, Z. A. Corrupção: dificuldades para definição e para um consenso. RAP, v. 30, n. 1, p. 6477, 1996. 
BRONARS, S. Campaign Donations Alter How a Politician Votes? Or, Do Donors Support Candidates who Value the Same Things that they do? Journal of Law and Economics, v. 40, n. 2, p. 317-350, 1997.

BROLLO, F. Who Is Punishing Corrupt Politicians: Voters or the Central Government? Evidence from the Brazilian Anti-Corruption Program. IGIER working paper, n. 336, 41 p., 2008.

BUCHANAN, J. M.; TUlLOCK, G. The Calculus of Consent: Logical Foundations of Constitutional Democracy. Ann Arbor, MI: University of Michigan Press, 1962.

CHAND, S. K.; MOENE, K. Controlling Fiscal Corruption. World Development, v. 27, n. 7 , p. 1129-1140, 1999.

CONTROLADORIA GERAL DA UNIÃO. Disponível em: <http://www.cgu.gov.br/>. Acesso em: 10 ago. 2013.

DEL MONTE, A.; PAPAGNI, E. Public expenditure, corruption, and economic growth: the case of Italy. European Journal of Political Economy, v. 17, p. 1-16, 2001.

.; _ The determinants of corruption in Italy: Regional panel data analysis. European Journal of Political Economy, v. 23, p. 319-396, 2007.

DONCHEV, D.; UJHELYI, G. What Do Corruption Indices Measure?. Social Science Electronic Publishing, p. 1-45, aug. 2009. Disponível em: <http://papers.ssrn.com/sol3/papers.cfm?abstract_ id=1124066>. Acesso em: 10 ago. 2015.

ESKElAND, G.; THIELE, H. Corruption Under Moral Hazard. Policy Research Working Papers Series, n. 2204, p. 1-32, 1999. Disponível em: <http://papers.ssrn.com/sol3/papers. cfm?abstract_id=623956>. Acesso em: 10 ago. 2015.

FERRAZ, C.; FINAN, F.; MOREIRA, D. B. Corrupção, Má Gestão, e Desempenho Educacional: Evidências a Partir da Fiscalização dos Municípios. In: ENCONTRO NACIONAL DE ECONOMIA, 36., 2008, Salvador. Anais eletrônicos... Salvador: ANPEC, 2008. Disponível em: <http://econpapers.repec.org/paper/anpen2008/200807211421560.htm>. Acesso em: 10 ago. 2015.

GOLDEN, M.; PICCI, L. Proposal for a New Measure of Corruption, Illustrated with Italian Data. Economics and Politics, v. 17, n. 1, p. 37-75, 2005.

JUNE, R. A Users' Guide to Measuring Corruption. 2008. Disponível em: <http://www.undp. org/content/dam/aplaws/publication/en/publications/democratic-governance/dg-publications-forwebsite/a-users-guide-to-measuring-corruption/users_guide_measuring_corruption.pdf>. Acesso em: 9 ago. 2015. 
HART, O. D; MOORE, J. H. Incomplete contracts and renegotiation. Econometrica, v. 56, p. $755-785,1988$.

HITE, N. Measuring Regional Variation of Corruption Induced Inefficiency in Public Roads Construction, using German Data. 2006. Disponível em: < http://citeseerx.ist.psu.edu/viewdoc/ summary?doi=10.1.1.537.2652 >. Acesso em: 8 ago. 2015.

JAIN, A. K. Corruption: a review. Journal of Economic Surveys, v. 15, n. 1, p. 71-121, 2001.

JOHNSON, O. E. G. An Economic Analysis of Corrupt Government, With Special Application to Less Developed Countries. Kyklos, v. 28, fasc.1, p. 47-61, 1975.

KAUFMANN, D.; KRAAY, A.; MASTRUZZI, M. Governance Matters VI: Governance Indicators for 1996-2006. World Bank Policy Research, Working Paper n. 4280, 105 p., 2006.

LIU, J.; LIN, B. Government Auditing and Corruption Control: Evidence from China’s Provincial panel data. China Journal of Accounting Research, v. 5, p. 163-186, 2012.

LUNA, F. E. Aplicação da metodologia de componentes principais na análise da estrutura a termo de taxa de juros brasileira e no cálculo de valor em risco. 2006. Disponível em: <http:// www.ipea.gov.br/portal/images/stories/PDFs/TDs/td_1146.pdf>. Acesso em: 11 ago. 2015.

MAURO, P. Corruption and Growth. The Quarterly Journal of Economics, v. 1, n. 3, p. 681$712,1995$.

Why Worry about Corruption. Economic Issues, n. 6, p. 1-19, 1997. Disponível em: Acesso em: 11 ago. 2015.

MITCHELL, William; SIMMONS, Randy. Para Além da Política: Mercados, Bens Estar e o Fracasso da Burocracia. Top Books, 2003

OLKEN, B. A. Corruption and the costs of redistribution: Micro evidence from Indonesia. Journal of Public Economic, v. 90, n. 4, p. 853-870, 2006.

Corruption perceptions vs. corruption reality. Journal of Public Economics, v. 93, n. 7-8, p. 950-964, 2009.

PERSSON, T.; G. TABELLINI, G. The Economic Effects of Constitutions. Cambridge, MA: MIT Press, 2003.

ROSE-ACKERMAN, S. The Economics of Corruption. Journal of Public Economics, v. 4, n. 2, p. 187-203, 1975.

Corruption: A Study in Political Economy. New York: Academic Press, 1978. 
Corruption and Government: Causes, Consequences, and Reform. Nova York: Cambridge University Press, 1999.

PARUOLO, P.; SAISANA, M.; SALTELLI, A. Ratings and rankings: Voodoo or Science? Journal of the Royal Statistical Society, v. 176, n. 2, p. 1-26, 2012.

SHLEIFER, A.; VISHNY, R. W. Corruption. Quarterly Journal of Economics, v. 108, p. 599618, 1993.

SPECK, B. W. Mensurando a Corrupção: uma revisão de dados provenientes de pesquisas empíricas. In: HOFMEISTER, W. (Org.). Os Custos da Corrupçáo. São Paulo: Fundação Konrad Adenauer, 2000. p. $9-45$.

SVENSSON, J. Eight questions about corruption. Journal of Economic Perspectives, v. 19, n. 3, p. 19-42, 2005.

TANZI, V.; DAVOODI, H. Corruption, Public Investment and Growth. IMF Working Paper, WP/97/139, p. 1-23, 1997. Disponível em: <https://www.imf.org/external/pubs/ft/wp/wp97139. pdf $>$. Acesso em: 10 ago. 2011.

TRANSPAREANCIA INTERNACIONAL. Definiçáo de corrupçáo. 2011. Disponível em: $<$ http://www.transparency.org>. Acesso em: 10 ago. 2011.

TREISMAN, D. The causes of corruption: a cross-national study. Journal of Public Economics, n. 76, p. 399, 2000.

. What Have We Learned About the Causes of Corruption from Ten Years of Cross-National Empirical Research? Annual Review of Political Science, v. 10, 211-244, 2007.

TRIBUNAL DE CONTAS DA UNIÃO. O que é o Cadastro de Contas Julgadas Irregulares?. 2013. Disponível em: <http://www.tcu.gov.br>. Acesso em: 5 ago. 2013.

Recebido em: 05.03.2015

Aceito em: 05.03.2015 


\section{Anexo I - Estatística descritiva das variáveis}

\begin{tabular}{lr}
\hline \multicolumn{1}{c}{$\operatorname{LOA}(\mathrm{R} \$)$} & \\
\hline Média & $45.278 .678 .259,97$ \\
Mediana & $39.543 .139 .361,00$ \\
Desvio Padrão & $14.439 .175 .273,39$ \\
Variância da amostra & $-0,14$ \\
Curtose & 1,19 \\
Assimetria & $208.489 .782 .575 .734 .000 .000,00$ \\
Mínimo & $31.088 .561 .692,00$ \\
Máximo & $73.425 .273 .183,00$ \\
\hline
\end{tabular}

Fonte: Elaborada pelos autores.

\begin{tabular}{lr}
\hline \multicolumn{2}{c}{ Cadirreg - Valor (R\$) } \\
\hline Média & $452.547 .386,70$ \\
Mediana & $316.563 .491,40$ \\
Desvio Padrão & $466.162 .930,70$ \\
Variância da amostra & 9,86 \\
Curtose & 0,88 \\
Assimetria & $217.307 .877 .962 .007 .000,00$ \\
Mínimo & $122.751 .073,94$ \\
Máximo & $1.829 .698 .384,68$ \\
\hline
\end{tabular}

Fonte: Elaborada pelos autores.

\begin{tabular}{lcc}
\hline \multicolumn{2}{c}{ Cadirreg - Número de processos } \\
\hline Média & 562 & \\
Mediana & 486 & \\
Desvio Padrão & 225 & \\
Variância da amostra & & 50.688 \\
Curtose & $-0,32$ & \\
Assimetria & & 1,01 \\
Mínimo & & 335 \\
Máximo & & 964 \\
\hline
\end{tabular}

Fonte: Elaborada pelos autores. 


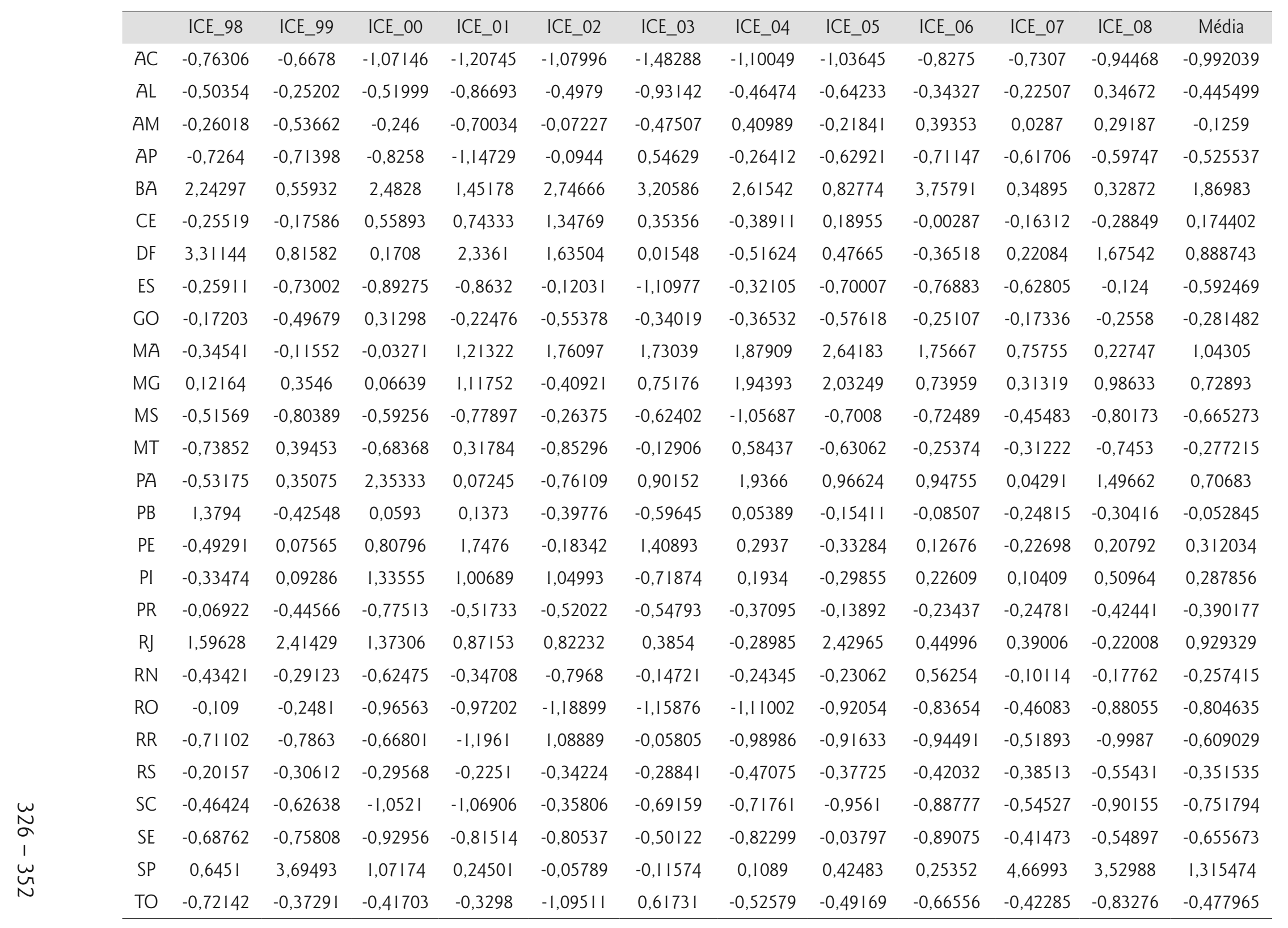




\section{A proposal for estimating regional corruption in Brazil}

\section{Abstract}

This article aims to present an alternative methodology to estimate the regional corruption in Brazil. It is known that corruption negatively affects the development of a region, but only recently have been detailed studies in this area. A large part of the existing indicators are based on national data and indicators of perceived corruption. For this methodology, we used the method of principal components and the objective information contained in the Register of Auditors Responsible Judged with Irregular (Cadirreg) for the period 1998 to 2008. The results for the average of the period indicate the states of Bahia, Maranhão and São Paulo as the most corrupt. Moreover, Acre, Rondônia and Santa Catarina was considered as de less corruption.

Keywords: Regional corruption. Method of principal components. Political economy. 